\title{
Refractory Thrombocytopenia
}

National Cancer Institute

\section{Source}

National Cancer Institute. Refractory Thrombocytopenia. NCI Thesaurus. Code C82594.

A myelodysplastic syndrome characterized by the presence of at least $10 \%$ dysplastic megakaryocytes, found within at least 30 megakaryocytes examined in the bone marrow. 